Revista Investigaciones Turísticas, no 13, pp. 178-203

ISSN: 2174-5609

DOI. http://dx.doi.org/10.14198/INTURI2017.13.09

JT Investigaciones

$\triangle$ surancenter TURISTCAS

\title{
La integración de los productos agroalimentarios de las tiendas "gourmet" en la oferta turística gastronómica de la ciudad de Córdoba
}

\author{
Ricardo David Hernández Rojas \\ Universidad de Córdoba \\ España \\ et2heror@uco.es
}

\author{
Manuel Rivera Mateos \\ Universidad de Córdoba \\ España \\ manuel.rivera@uco.es
}

\author{
María Genoveva Millán Vázquez de la Torre \\ Universidad Loyola de Andalucía \\ España \\ gmillan@uloyola.es
}

\section{RESUMEN}

Este trabajo tiene por objeto el estudio de los establecimientos comerciales de productos agroalimentarios especializados tipo gourmet o delicatessen en un destino de turismo urbano cultural como es la ciudad de Córdoba, centrándose en las relaciones y sinergias existentes con su dinámica urbana reciente, la oferta turística general de la ciudad y la oferta gastronómica local y provincial. Igualmente se analiza la localización geográfica de estos establecimientos, las categorías de productos comercializados, sus condiciones de acceso al mercado local y su visibilidad real en la oferta turística local.

Del análisis realizado se desprende que, pese a las importantes potencialidades de estos negocios para la consolidación y posicionamiento de la imagen de Córdoba como destino excelente de turismo gastronómico, existe un nivel bajo de integración y vinculación entre este tipo de comercio, la propia ciudad y la oferta turística urbana, lo que exige una redefinición de sus estrategias comerciales y de sostenibilidad y su adecuada inserción en la cadena de valor de la oferta gastronómica local y provincial.

Palabras clave: tiendas "gourmet"; productos agroalimentarios; turismo gastronómico; denominaciones de origen; Córdoba 


\title{
Integration of food products from gourmet stores in the culinary tourism offering in the city of Córdoba
}

\begin{abstract}
This paper addresses the study of commercial establishments specialized on gourmet/delicatessen food products in an urban touristic destination such as Córdoba. The study focuses on the synergies and connections with the urban dynamics, the general touristic attractions in the city and, more specifically, with the gastronomic offerings in the city and the region. Firstly, we analyze the gourmet store market, locations, product categories and distribution channel access to the local market. We study the difficulties inherent in the insertion and actual visibility of these products in the local touristic offering.

We identify and enumerate deficiencies, weaknesses and opportunities to enrich the touristic offering and to expose and consolidate the image of Córdoba as a culinary tourism destination of excellence. Finally, is detected the need for a redefinition of its commercial and sustainability strategies and its adequate insertion in the value chain of the local and regional gastronomic offer.
\end{abstract}

Keywords: gourmet stores; food products; culinary tourism; gastronomic tourism; designation of origin; Cordoba

\section{INTRODUCCIÓN}

Desde finales del siglo $X X$, se observa una corriente creciente de turistas más selectivos respecto a los destinos turísticos que eligen y las motivaciones para visitarlos, entre las que podemos destacar la gastronomía, enraizada en la cultura del lugar. El turismo gastronómico, en este sentido, se puede definir como una modalidad de turismo cultural donde la motivación principal del viaje de las personas que lo realizan a un destino concreto es su gastronomía y cultura culinaria (Hall y Sharples, 2003). El turismo gastronómico engloba, a su vez, a diferentes subtipologías turísticas entre las que destaca el oleoturismo, referido al aceite y las visitas a almazaras o el enoturismo, referido al vino y las visitas a lagares y bodegas, pudiéndose definirse otras muchas en función de los productos principales que integran las rutas y destinos visitados (Vizcaino, 2015). En cualquier caso, tal como lo entendemos hoy día, este tipo de turismo trata de fusionar la actividad turística vinculada a la gastronomía con el disfrute y el conocimiento de un territorio en toda su integridad, incorporando no sólo productos agroalimentarios sino también patrimonio, experiencias, paisajes, valores y tradiciones en torno a la cadena productiva de dichos recursos alimentarios. El concepto de turismo gastronómico, en efecto, ha evolucionado con el tiempo amplificando sus escenarios y ligándose cada vez más con la "cultura" de los lugares visitados (Scarpato, 2002). 
La gastronomía, particularmente en las últimas décadas, se ha convertido en un elemento muchas veces consustancial de la oferta turística de destinos de todo tipo, tanto urbanos, como rurales o de sol y playa. Y aun cuando no constituye la mayoría de las veces la principal motivación de la visita o ni tan siquiera es de carácter prioritario, no cabe duda de que al menos se conforma como un producto complementario básico, fuertemente dinamizador, enriquecedor y diferenciador de los destinos visitados. Incluso progresivamente las experiencias gastronómicas bien articuladas con su entorno cultural, paisajístico y geográfico y con el resto de la oferta turística local o regional, pueden llegar a convertirse en una atracción fundamental con capacidad de generación de importantes flujos turísticos (Oliveira, 2011).

Los cambios de finales de la década de los ochenta y de los años noventa del siglo XX que permearon otras esferas de la sociedad, de la economía y los hábitos de vida, constituyen y sitúan el marco temporal de punto de encuentro de los sectores del turismo y la producción agroalimentaria dando lugar a la aparición del turismo gastronómico (Hall y Page, 1999). Paralelamente en ese período se produce un creciente interés de la población por seguir dietas alimentarias saludables generando nuevas tendencias en los hábitos alimentarios y sobre todo una nueva concepción de la naturaleza y el significado de los alimentos (Alvares y Alvares, 2009). La gastronomía y la alimentación en general siempre han estado ligadas al turismo y es ciertamente significativo el volumen de gasto turístico mundial (OMT, 2012) como su carácter dinámico y creativo como segmento turístico, si bien su relevancia real en la experiencia turística no está bien estudiada aún.

Hoy día, como resultado también de la industrialización y la globalización, muchos turistas buscan nuevas señas de identidad en las sociedades postmodernas, de manera que la alimentación se ha convertido en un instrumento de búsqueda de las mismas y, además, identifica a las poblaciones y los territorios en muchos casos, como ocurre con la alta cocina francesa (Petrini, 2007), por lo que incluso se utiliza como importante elemento de promoción turística (Richards, 2002). No es extraño entonces que la relación "lugar-gastronomía" también haya sido utilizada en turismo para dicha promoción en lo que respecta a la utilización de distintivos de los productos agroalimentarios típicos, tanto nacionales como regionales. Los turistas y los consumidores en general son hoy por hoy cada vez más conscientes de lo que consumen y de su relación con el medio en el que viven, lo que ha incrementado la demanda de consumo de los productos locales en línea con las tendencias de los nuevos estilos de vida más saludables y la defensa de valores éticos y sostenibles en relación con los territorios, los paisajes, la cultura local o los productos típicos y tradicionales, que precisamente constituyen la espina dorsal del turismo gastronómico (Leal, 2013). La tendencia de los consumidores hacia sistemas de producción y abastecimiento alimentario alternativos a la producción agroindustrial unida a la búsqueda de formas experienciales de hacer turismo es precisamente lo que ha forjado el turismo gastronómico.

En este contexto los productos agroalimentarios "gourmet" se ponen de moda por su calidad, su elaboración generalmente artesanal, su carácter local, alternativo y auténtico al ser producidos por pymes o micropymes, su oferta limitada y uso atípico y su propia exclusividad (Boniface, 2003; Watts et al., 2005), al estar disponibles únicamente en establecimientos de venta tipo gourmet, speciality o delicatessen, a los que podemos añadir los especializados en 
producción de agricultura ecológica y cocina étnica, entre otros. Pero en este punto se plantea en este artículo la necesidad de una primera aproximación de situación, discusión y debate que indague en las relaciones del turismo urbano y los establecimientos gastronómicos: si existe un segmento de mercado de los productos agroalimentarios tipo gourmet bien orientado hacia el turismo, si los puntos de venta están debidamente integrados en la oferta turísticogastronómica local como actores implicados y relevantes, si están contribuyendo realmente a una experiencia de calidad por parte de los visitantes en el destino y si las tiendas gourmet realmente están beneficiándose del desarrollo turístico de ciudades patrimoniales como Córdoba. Y es que, si la investigación en turismo gastronómico es relativamente abundante, resulta, en cambio, escasa sobre los aspectos relacionados con su vinculación con algunas actividades y establecimientos como los que aquí estudiamos.

En principio, la gastronomía puede tener una influencia significativa en la experiencia turística de los visitantes y ser consecuentemente una alternativa para la emergencia de aquellos destinos que no pueden beneficiarse del turismo de masas o para la reactivación de otros que sufren una etapa crítica o de estancamiento en su ciclo de vida. De igual manera, los actores de la cadena de abastecimiento y comercialización de productos agroalimentarios con una demanda local aún reducida como las tiendas gourmet pueden entrar en el mercado del turismo gastronómico y percibir éste como una oportunidad de negocio. No obstante, han de darse una serie de factores y premisas previas como una localización adecuada en la cadena referida en términos de conectividad, infraestructura y equipamiento turístico, acceso a la información y a la cobertura de promoción turística del destino y determinados vínculos con otros actores de proximidad (productores y consumidores potenciales) y con organizaciones con las que crear redes colaborativas, además de una estrategia promocional turística relacionada con el sector de la alimentación (Leal, 2013).

Todos estos aspectos son ciertamente fundamentales para la viabilidad del turismo gastronómico y constituyen la base fundamental para las nuevas formas de comercialización, organización y relación de la cadena agroalimentaria a la que nos referimos. En este sentido, una de las nuevas formas de comercialización en el ámbito turístico-agroalimentario, así como de diferenciación competitiva de productos, son las Indicaciones Geográficas Protegidas (IGP) y, más particularmente, las Denominaciones de Origen Protegidas (DOP), que juegan un papel importante en el proceso de creación de valor, diferenciando el origen vinculado al producto de otros de la misma categoría. Estas integran, por tanto, en su definición no sólo el origen geográfico sino, de una forma relevante, la tradición y especialización a la hora de elaborar productos de alta calidad y con personalidad diferente, así como la reglamentación y los mecanismos de control sobre su producción (Márquez y Hernández, 2001), que las micropymes o pymes productoras y/o comercializadoras no podrían asumir por sí solas (Torres, 2012).

Los operadores de la cadena de suministro con el fin de adaptarse a la demanda del mercado y responder de manera proactiva a las exigencias de calidad por parte de los consumidores, se apoyan en este valor añadido como sellos de distinción de productos con atributos específicos (Weatherell et al., 2003). Y, además, los operadores de origen intentan conectar con los consumidores locales y los visitantes de manera localizada mediante la venta

Investigaciones Turísticas

$\mathrm{N}^{\circ} 13$, enero-junio 2017, pp. 178-203 
de sus productos directamente al consumidor a través de cadenas de alimentos alternativos y tiendas gourmet o delicatessen. Estos últimos establecimientos en destinos urbanos como el que estudiamos aquí, en la medida en que muestran y comercializan los productos de las certificaciones y denominaciones geográficas de protección y calidad, actúan como instrumento relacional importante entre los productores y consumidores fuera muchas veces del lugar de producción en zonas rurales de la provincia. De hecho, los turistas acaban comprando estos productos y los trasladan desde los destinos visitados y lugares de origen y/o producción hasta sus domicilios, donde son consumidos a modo de "souvenirs gastronómicos" como forma de consumo turístico (Richards, 2002).

a venta directa in situ asociada a actividades turísticas o de ocio se está convirtiendo precisamente en un nicho de mercado característico del turismo gastronómico que surge por la necesidad de diversificación de la oferta de los establecimientos minoristas de alimentación especializada, representando una oportunidad importante para los productos locales y regionales a la hora de acceder a un mercado más amplio. De esta manera, surgen también diversas estrategias de comercialización de productos agroalimentarios a través, sobre todo, de rutas y tours gastronómicos, a modo de itinerarios temáticos asociados a un producto o plato típico de una determinada zona geográfica o Denominación de Origen conocida (Millán y Morales, 2012; Fandos et al., 2012), pudiendo también tratarse de rutas culinarias étnicas asociadas al turismo identitario y rutas históricas (Tresserras et al., 2007). La información acerca de los productos especializados y autóctonos encuentra precisamente aquí un medio instrumental y un espacio de interacción adecuado para acercar a los diferentes actores en la cadena, conectar directamente los productores con las tiendas comerciales y los turistas o excursionistas (Boniface, 2003) e invitar a éstos a visitar el destino y disfrutar de experiencias en su entorno paisajístico y cultural integrado por diversos componentes materiales e inmateriales, que finalmente conforman un macroproducto turístico complejo.

De esta manera, puede entenderse cómo el desarrollo y la consolidación de los destinos de turismo gastronómico están directamente relacionados con la gestión de los establecimientos, servicios y recursos patrimoniales que les sirven de base y soporte, pero también y sobre todo con el funcionamiento óptimo de las relaciones entre actores en la cadena de abastecimiento y comercialización de los productos agroalimentarios y su capacidad de generar un macroproducto turístico atractivo. Esto unido a la calidad de sus entornos culturales y paisajísticos, puede constituirse incluso en un elemento diferenciador que permita al destino una posición competitiva respecto a otros territorios. Y para ello sus responsables han de realizar importantes esfuerzos para ofrecer una experiencia de calidad y mantener su capacidad de atracción turístico-comercial, de manera que han de estar cada vez más abiertos a la colaboración con otras ofertas, entidades y agentes, al tiempo que más próximos a la lógica empresarial y comercial, teniendo en cuenta su preocupación por los problemas de viabilidad, financiación y rentabilidad (Merinero y Zamora, 2009).

La producción y la oferta efectiva de turismo gastronómico exige la integración de un complejo rango de actividades y servicios dentro y entre una serie de unidades de producción (empresas, establecimientos, actividades, equipamientos, sistemas de producción agroalimentaria, etc.) que contribuyan a la creación de valor (Clocke et al., 2011) y entre las que 
incluiríamos también a las tiendas gourmet. Esto implica, por otro lado, su adaptación especial a las exigencias de la función turística para aumentar su capacidad de influencia y capacidad de reclamo para los turistas, lo que también puede beneficiar la atracción de la demanda de los propios visitantes locales. Pero además las estrategias diseñadas por las administraciones públicas con competencias en turismo y comercio han de promover acciones adecuadas para la integración de estos dos subsectores económicos (turístico y agroalimentario), dirigidas a mejorar la competitividad del destino y los agentes y establecimientos que lo nutren en este nicho de mercado.

El presente trabajo, motivado por la comprensión de las relaciones e interacciones de quienes participan de la cadena de comercialización y distribución de productos agroalimentarios en el marco del turismo gastronómico, encuentra en el concepto de "cadena de valor" desarrollado desde la economía y aplicado al análisis geográfico de los sistemas agroalimentarios así como en el enfoque de la dinámica relacional, los elementos necesarios para explicar mejor el fenómeno que vincula dos sectores de actividad: el comercio agroalimentario especializado tipo gourmet y el turismo. $\mathrm{Y}$ esto nos permitirá también aproximarnos al turismo gastronómico desde la perspectiva de su funcionalidad como estrategia para el desarrollo local, de la existencia o no de beneficio para los actores que forman parte del proceso de abastecimiento, distribución y comercialización de productos agroalimentarios dentro del turismo gastronómico y, cómo no, de la contribución de aquéllos a la consolidación y desarrollo de este segmento de demanda turística.

\section{LA CONTEXTUALIZACION DE CÓRDOBA COMO DESTINO DE TURISMO GASTRONÓMICO: RUTAS, COMERCIO DE PRODUCTOS GOURMET Y OFERTA DE RESTAURACION}

Córdoba, como ciudad de interior situada en la región más meridional de España, cuenta con una ubicación privilegiada en cuanto a comunicaciones tanto por AVE como por carretera. En ella el sector servicios es el que tiene carácter mayoritario en su economía local y dentro de éste la principal actividad económica es el turismo. En los últimos años, después del estancamiento motivado por la crisis económica, el turismo ha vuelto a ser el principal motor económico y el primer sector en comenzar a salir visiblemente de la crisis, de manera que desde las instituciones locales se han priorizado una serie de medidas para la planificación estratégica y el fomento de esta actividad en Córdoba, la atracción y fidelización de turistas, la diversificación de los mercados emisores y los segmentos de demanda - entre los que el turismo gastronómico adquiere una importante relevancia-, la mejora de la competitividad de las empresas turísticas y el incremento de la rentabilidad y sostenibilidad del sector en la ciudad (Escuela de Organización Industrial, 2014). Asimismo, la ciudad cuenta con un Plan Turístico de Grandes Ciudades en ejecución, convenido entre las Administraciones Local y Autonómica, que intenta favorecer el desarrollo de esta actividad creando nuevos productos turísticos que mejoren y diversifiquen la oferta existente.

Córdoba despunta, asimismo, a nivel nacional como destino cultural dentro de las Ciudades Patrimonio de la Humanidad, con tres declaraciones al respecto: en 1984 la Unesco

Investigaciones Turísticas

$\mathrm{N}^{\circ} 13$, enero-junio 2017 , pp. $178-203$ 
reconoció a la Mezquita-Catedral como Patrimonio de la Humanidad; diez años después (1994) este reconocimiento fue extendido al Centro Histórico de la ciudad, que posee una gran riqueza monumental conservando grandes vestigios de la época romana, árabe y cristiana, y en el 2012 la Fiesta de los Patios se consideró Patrimonio Inmaterial de la Humanidad. Estos reconocimientos hacen de esta ciudad de interior un lugar culturalmente interesante para ser visitado, pero hay que añadir también la rica gastronomía, mezcla de culturas, tanto por la variedad de los platos como por la calidad de los productos que se utilizan, lo que hacen de esta ciudad un destino gastronómico de excelencia y cada vez más reconocido a nivel nacional (López y Sánchez, 2012; Millán y Hernández, 2015). La restauración emerge hoy día de las ricas y profundas tradiciones ancestrales e interculturales de la gastronomía cordobesa, pero en perfecta simbiosis con la nueva cocina innovadora donde destaca la obra de conocidos restaurantes, cocineros y gourmets de fama nacional e internacional (Villegas, 2012).

La propia evolución y crecimiento de la oferta de establecimientos hoteleros y de restauración turística en la ciudad en las dos últimas décadas ${ }^{1}$ ha contribuido a la mejora y consolidación de la imagen de Córdoba como destino de turismo gastronómico. No pocos hoteles de gama media-alta incorporan en sus establecimientos a restaurantes de alto interés gastronómico y tras la crisis económica de los últimos años -que supuso el cierre de un número no desdeñable de restaurantes- este tipo de negocios está aumentando significativamente y diversificando su oferta (cocina halal, cocina kosher, cocina mediterránea, cocina fusión, cocina tradicional cordobesa...). Hay que considerar, además, que dentro de los subsectores turísticos o paraturísticos de la ciudad el de cafeterías y restaurantes supuso en 2010 una partida de gasto turístico de más de 23 millones de euros, sólo por debajo del subsector de alojamiento ${ }^{2}$ y con un importante efecto multiplicador (efecto indirecto) en otros subsectores de actividad. Esta evolución favorable de la oferta hotelera y de restauración ha sido, en principio, muy positiva para la demanda de productos locales "gourmet", sobre todo por el efecto promocional y de imagen mediática que se ha ganado la gastronomía cordobesa ligada a estos establecimientos turísticos, pero no tanto -como ya veremos en el apartado de resultados de este artículo- por la existencia de sinergias favorables, colaborativas y efectivas, entre las tiendas gourmet y dichos establecimientos alojativos y de hostelería.

Como ejemplo importante también de la emergencia y desarrollo del turismo gastronómico en la provincia de Córdoba hemos de destacar la conformación de varias rutas gastronómicas, en diferente estado de madurez, que han ido articulándose a partir de productos agroalimentarios típicos, que cuentan, en la mayor parte de los casos, con Denominaciones de Origen. Por la importancia de estos itinerarios para el desarrollo y viabilidad del comercio especializado gourmet en la ciudad de Córdoba hemos de relacionar concretamente los siguientes (Figura 1):

Ruta del Vino de Montilla-Moriles en la D.O.P. homónima, sin duda la de promoción y conformación más antigua en la provincia, si bien su estructuración formal y oficial data de

\footnotetext{
${ }^{1}$ De 2002 a 2015 se ha producido un incremento del número de hoteles de un 34\% y de pensiones y hostales en un $8 \%$, de acuerdo con los datos del Informe Anual del Observatorio Turístico de Córdoba (Consorcio de Turismo de Córdoba, 2016). Asimismo, entre 1998 y 2010 (período para el que se disponen de datos del Registro de Turismo de Andalucía), el número de restaurantes crecieron en la ciudad cerca del 10\%. (Eseca, 2010).

${ }^{2}$ Datos de las Tablas Input Output elaboradas por el Observatorio Turístico de Córdoba en 2010 (Eseca, 2010).
} 
principios de este siglo a través de la ejecución de un Plan de Dinamización de Producto Turístico convenido entre la asociación ACEVIN de Rutas del Vino, los municipios de la D.O.P., entre los que se encuentra Córdoba capital, y la Administración Turística Estatal y Regional.

Rutas del Aceite de las D.O.P. de Baena, Montoro-Adamuz, Priego de Córdoba y Lucena, que cubren una parte importante del territorio del sur de Córdoba.

Ruta del Jamón Ibérico de la D.O.P. de la comarca de Los Pedroches, en el norte de la provincia y con enlace final también con la capital cordobesa.

Ruta del Anís y del Mantecado de Rute, con epicentro en esta localidad de las Subbéticas Cordobesas y, sin duda, la más consolidada a nivel provincial pese a su carácter más efímero desde el punto de vista temporal y estacional, ya que cuenta con una gran promoción y proyección a nivel regional y nacional y ha conseguido una oferta de turismo gastronómico singular de anisados y dulces centrada en las fiestas navideñas, prenavideñas y de fin de año, siendo su primer mercado real y potencial de proximidad la misma ciudad de Córdoba.

Ruta de las Tabernas de Córdoba, centrada en Córdoba capital y en la cocina de tapas tradicionales y autóctonas, tratándose de un itinerario por tabernas típicas y tradicionales también muy promocionado desde hace bastantes años.

A lo largo de las rutas un elemento fundamental es, sin duda, el conjunto de los establecimientos comerciales minoristas y tiendas gourmet o especializadas en los que pueden adquirirse los productos agroalimentarios de la zona y conocer directa o indirectamente la oferta culinaria local y regional. Pero también en estos itinerarios gastronómicos podemos encontrar otro tipo de establecimientos que juegan diferentes papeles en la conformación del macroproducto turístico final pero que, en mayor o menor medida, suelen incluir algún servicio de venta directa de productos culinarios: restaurantes y mesones rurales, alojamientos, mercados gastronómicos, bodegas, almazaras y otras instalaciones agroindustriales, empresas de servicios turísticos, museos temáticos y centros de interpretación, etc. Y es precisamente el nivel de integración y sinergias entre estos establecimientos y servicios y el grado de vinculación de los mismos con la producción alimentaria y la promoción turística del destino/ruta lo que ha de considerarse como básico en cualquier estrategia promocional de la zona que permita identificar la misma con la marca turística (Armestoy Gómez, 2004). 
Figura 1. Mapa de rutas gastronómicas de Córdoba y provincia

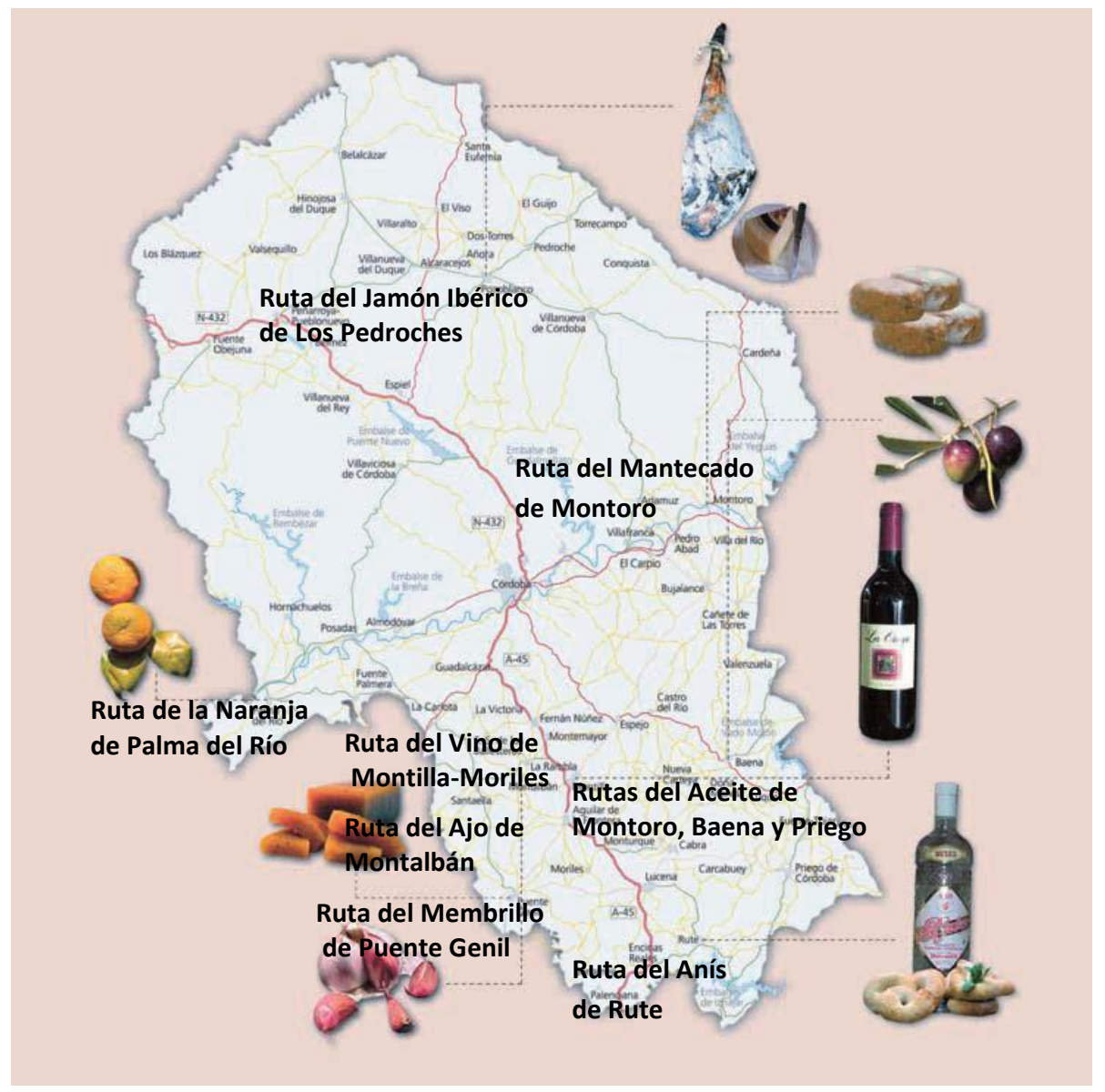

Elaboración propia.

En la ciudad de Córdoba el desarrollo del comercio especializado gourmet hay que enmarcarlo en los cambios profundos que ha vivido el comercio urbano en general. En concreto, hemos de reseñar la modernización de las empresas comerciales, la irrupción de nuevos hábitos de consumo y de uso de su casco histórico tradicional, la crisis de los formatos tradicionales de venta directa de productos alimentarios y el cambio de tendencia que ha acabado por buscar el éxito comercial en la especialización y diferenciación y en la búsqueda de nuevos mercados como el turístico. En el Conjunto Histórico de Córdoba se ha registrado en las últimas décadas una pérdida del comercio tradicional alimentario paralelo a un despoblamiento demográfico relativamente acusado, con la consecuente pérdida en algunas zonas, como los populares Barrios de San Basilio-Alcázar Viejo y la Judería, de servicios básicos como el aprovisionamiento comercial, todo ello con el consecuente decaimiento funcional que ello conlleva, denominado por algunos autores como "fooddeserts" (Whelan, Wrigley, Warm, y Cannings, 2002). Pues bien, esta especialización y diversificación ha abierto en Córdoba, al menos, como en otras ciudades patrimoniales e históricas, nuevas perspectivas para el comercio tradicional facilitando la revalorización del espacio urbano comercial con problemas de sostenibilidad frente a los nuevos ejes comerciales centrales o semicentrales y las grandes superficies comerciales suburbanas que han ido apareciendo en la ciudad en las dos últimas décadas. 
Las tiendas de alimentación especializada o comercios gourmet o delicatessen han respondido en esta coyuntura de cambios ofertando un surtido exclusivo y diferencial de productos de alimentación nacional, regional o local de alta calidad. Dado que este concepto de tienda se está consolidando en ciudades turísticas y patrimoniales relevantes como Córdoba es necesario conocer la visión que de las mismas tienen sus comerciantes, el grado de implicación que tienen con su entorno urbano y la oferta y demanda turística a través de sus establecimientos físicos, así como el potencial que el desarrollo de este tipo de comercios puede tener en la revitalización comercial y turística del centro histórico y áreas urbanas colindantes, aquejadas de su pérdida de centralidad comercial. Y es que esta temática de estudio relacionada con la importancia del comercio en el buen funcionamiento del territorio urbano, de sus áreas comerciales tradicionales y del desarrollo de la actividad turística en sus centros históricos, si bien ha sido objeto de reflexión desde los años ochenta en otros destinos urbanos españoles e incluso anteriormente en el Norte de Europa y otros países occidentales como Estados Unidos (Espinosa, 2009), en Córdoba adolece de análisis empíricos, tanto generales como parciales.

Además de esta ausencia de estudios y antecedentes de investigación en la ciudad de Córdoba sobre este tema, nos encontramos con una dificultad añadida como es la falta de información específica, tanto cualitativa como cuantitativa, sobre los establecimientos que estrictamente pueden englobarse en la categoría denominada Delicatessen o Gourmet. Así, a diferencia de otros subsectores económicos como el de los congelados, donde sólo una característica determinada por el estado del producto permite fácilmente identificar a las empresas que los producen, a sus consumidores y los productos finales, la industria delicatessen en términos de productos, empresas participantes y consumidores no tiene una definición única y el valor percibido por los consumidores es ciertamente variable (Indap, 2005). A la hora de definir estos establecimientos comerciales existen, en fin, importantes dificultades desde diversos puntos de vista, sobre todo por la falta de homogeneización terminológica y tipológica y la escasez de estudios centrados en los propios comercios que distribuyen estos productos, siendo finalmente complicada la tarea de acotar los productos que deben ser vendidos en los mismos y qué servicios deben prestar las tiendas especializadas (Espinosa, 2011).

Incluso en una ciudad como Córdoba donde no son precisamente numerosas las tiendas gourmet, estos establecimientos son relativamente variados, por lo que resulta algo difícil establecer rasgos comunes: tiendas y restaurantes de comida étnica, tabernas típicas con venta complementaria de productos autóctonos de calidad, restaurantes con tiendas gourmet asociadas y degustaciones, tiendas de productos naturales o ecológicos, tiendas de quesos, panaderías, confiterías, pequeñas tiendas de barrio o establecimientos de marcas comerciales con productos de D.O.P. Estos establecimientos venden un amplio rango de productos poco comunes que no se encuentran con facilidad en los supermercados y otros canales masivos. De hecho, las tiendas gourmet utilizan una estrategia de marketing muy distinta a la de los supermercados: no se concentran en grandes volúmenes de ventas, sino que se dedican a encontrar nuevos productos que diferencien su negocio del resto, de manera que el comercio de alimentación especializada, de alto valor añadido, de "elaboración excepcional" y de "identificación propia” serían sus características más definitorias. 
La consolidación del turismo gastronómico en ciudades como Córdoba depende en buena parte de la capacidad de los agentes implicados para articular productos y servicios específicos que se adapten a la demanda turística y a las necesidades reales de los consumidores, de manera que el conocimiento del perfil de éstos debe ser una prioridad de investigación, como hemos podido comprobar en nuestro caso con el consumo de los productos de las tiendas gourmet, y ello más aún por la opacidad o práctica inexistencia de información estadística y registral y la suma escasez de estudios específicos de referencia a nivel nacional, regional o local en España. En el caso de Córdoba el primer problema al que nos enfrentamos es la suma dificultad de poder determinar la suficiencia de la oferta de estos establecimientos para cubrir la demanda actual y a corto y medio plazo, dado que apenas contamos con datos sobre consumidores reales y potenciales. El propio Observatorio Turístico de la ciudad de Córdoba apenas facilita información cuantitativa y cualitativa sobre el subsector de restauración en la ciudad y menos aún sobre el comercio tradicional y otros subsectores de indudable interés para la demanda turística como la artesanía, el comercio tradicional de productos locales genuinos y el de las propias tiendas gourmet. En consecuencia, la disposición en las encuestas a visitantes de la ciudad de Córdoba de preguntas relativas a la demanda y valoración sobre este tipo de establecimientos se hace sumamente necesaria (Hernández, 2016).

\section{METODOLOGÍA DE LA INVESTIGACIÓN}

La investigación que presentamos se ha realizado a través de un análisis cuantitativo y cualitativo por medio de una encuesta directa a una muestra amplia y representativa de tiendas gourmet y/o delicatessen de la ciudad de Córdoba. Las encuestas a estos establecimientos se realizaron durante los meses de mayo y junio del año 2015, coincidiendo con la temporada alta turística en Córdoba y mediante visitas físicas a las diferentes tiendas. Como algunas preguntas iban en relación directa con las características particulares de estos establecimientos y el merchandising de los productos ofertados, se pudo corroborar directamente la veracidad de las respuestas, además de profundizar in situ en otros aspectos cualitativos de interés a través de preguntas abiertas y comentarios de libre realización por parte de los encuestados.

La encuesta, por otra lado, fue realizada en todas las zonas o barrios de la ciudad de Córdoba con alguna presencia de tiendas especializadas en productos gourmet, no precisamente numerosas por cierto en su totalidad, de modo que prácticamente se amplió el radio de análisis a todo el conjunto urbano e incluso suburbano, donde pueden encontrarse algunas grandes superficies comerciales con alguna tienda o sección de ventas de productos gourmet, bien como establecimiento independiente dentro del centro comercial o como punto de venta en el mismo supermercado patrocinado por la marca comercial identificativa de la gran superficie.

El cuestionario de la encuesta fue estructurado en un total de 20 preguntas, clasificadas y agrupadas en diversos apartados temáticos y de contenidos, a saber:

1.) Aspectos de estructura económica de la tienda gourmet. Se trata de conocer el tipo de establecimientos con los que nos encontramos y algunos datos básicos como el número de 
empleados, número de tiendas, formación y cualificación de los empleados en la misma tienda, etc. (Tabla 1).

2.) Aspectos de comercialización de los productos y su vinculación con rutas gastronómicas, cuestiones vinculadas a la misma, etc. Se trata de ver si se apoyan en D.O.P. o I.G.P. de la provincia para comercializar sus productos, si tienen vinculación con la oferta y la promoción turística de la ciudad, si mantienen relaciones con los establecimientos y agentes turísticos, etc.

3.) Aspectos cualitativos sobre el turismo urbano y sobre los clientes. Se trata de aspectos importantes para conocer la relación comercio-ciudad-turismo, tales como el perfil del turista consumidor, la integración de los establecimientos en la oferta turística urbana y sus sinergias con los agentes locales de turismo, etc.

Una vez fueron codificados los cuestionarios se procedió a la realización de un análisis univariante del que se obtuvieron los principales resultados que se exponen en el apartado siguiente.

Asimismo, se cartografiaron y localizaron todos los establecimientos comerciales gourmet identificados en la ciudad a través de diversas fuentes de información (Registro de Comercio, trabajo de campo, medios de promoción turística, medios especializados en Internet, etc.), con el objeto de interrelacionar adecuadamente las ubicaciones geográficas de estos locales con el entorno urbanístico, turístico y comercial de Córdoba e intentar establecer causas explicativas de dicha localización.

\section{RESULTADOS Y DISCUSIÓN}

El análisis descriptivo de la encuesta realizada ha arrojado los siguientes resultados principales que resumimos y comentamos a continuación:

Con respecto al tamaño de las empresas, un $90 \%$ de las tiendas gourmets son pymes e incluso en su mayoría micropymes de estructura familiar, contando, asimismo, en su mayoría (un $75 \%$ ) con una sola tienda abierta al público (Tabla 1 ). 
La integración de los productos agroalimentarios de las tiendas "gourmet" en la oferta turística gastronómica de la ciudad de Córdoba

Tabla 1. Estructura económica de las tiendas gourmet

\begin{tabular}{|c|c|c|}
\hline Pregunta & & Porcentaje \\
\hline \multirow{2}{*}{ Número de empleados } & $1-4$ empleados & $80,00 \%$ \\
& 5 a 9 empleados & $10,00 \%$ \\
& más de 10 empleados & $10,00 \%$ \\
\hline \multirow{2}{*}{ ¿Tiene más de un establecimiento? } & Si & $25,00 \%$ \\
& No & $75,75 \%$ \\
\hline \multirow{2}{*}{ Ubique la zona del establecimiento } & Zona centro & $25,00 \%$ \\
según su criterio & Zona turística (mezquita, rio, Judería) & $25,00 \%$ \\
& Zona de Barrio & $5,00 \%$ \\
\hline
\end{tabular}

Elaboración propia

La zona donde se ubican más tiendas gourmet coincide con la de mayores flujos turísticos, la Judería-La Ribera-Centro Histórico Comercial, con un $45 \%$ del total de las tiendas alimentarias especializadas de la ciudad (Figura 2). En cambio, donde menos se localizan es en los centros y grandes superficies comerciales (sólo un 5\%). La distribución geográfica de los establecimientos es más equitativa, sin embargo, entre la zona centro de la ciudad y las zonas de barrio semicentrales o más periféricas (Gráfico 1), correspondiéndose éstas últimas con barrios modernos de expansión urbana reciente y/o con una población joven-adulta de clase media o clase media-alta sensibilizada con este tipo de productos (Zoco Córdoba, Arroyo del Moro, El Brillante, Vial Norte, Tablero Bajo, El Brillante).

Partiendo de estas consideraciones generales, en Córdoba ciudad hemos tratado de identificar los establecimientos de venta final minorista de productos agroalimentarios gourmet o similares que operan en la ciudad, con el objeto de conocer y comprender sus características, intereses y valores, los mecanismos que orientan su toma de decisiones de comercialización , sus estrategias para alcanzar objetivos y sus posibles interacciones con la oferta y la demanda de turismo gastronómico en la ciudad.

Gráfico 1. Ubicación urbana de las tiendas gourmet

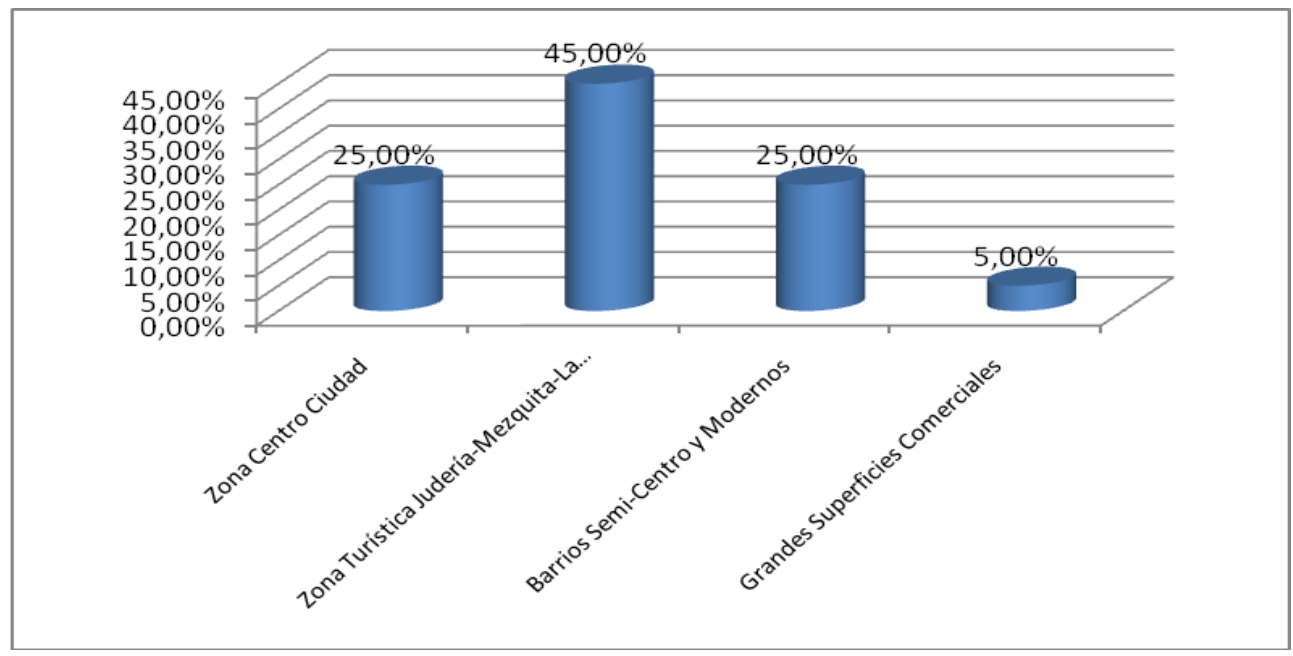

Elaboración propia

Investigaciones Turísticas

$\mathrm{N}^{\circ} 13$, enero-junio 2017, pp. 178-203 
Las tiendas gourmet cordobesas están ubicadas en distintas zonas o barrios de la ciudad (Figura 2), pero con la excepción de las integradas en grandes superficies comerciales suburbanas y en el nuevo Mercado Gastronómico Agora 83 en el barrio del Brillante, todas ellas buscan espacios centrales, zonas urbanas con población de niveles de ingresos elevados y profesionales o público sensibilizado con la alimentación saludable y de calidad, además de los enclaves del Conjunto Histórico con importantes flujos turísticos y de visitantes, principalmente en el eje Judería-Mezquita/Catedral-Tendillas-Paseo de la Victoria, donde además existen dos Mercados Gastronómicos de reciente creación (La Victoria y Patios de la Marquesa). Las tiendas existentes en la capital no son, por otro lado, específicas o exclusivas de ninguna D.O.P. o de un producto o variedad de productos en concreto, salvo alguna excepción como la tienda de la Cooperativa Ganadera del Valle de Los Pedroches (COVAP), en pleno centro de la ciudad. En definitiva, suelen comercializar productos variados que para la percepción de los clientes están considerados como de alta calidad y de características diferenciadas.

Figura 2. Plano de Córdoba con la ubicación de las tiendas gourmet

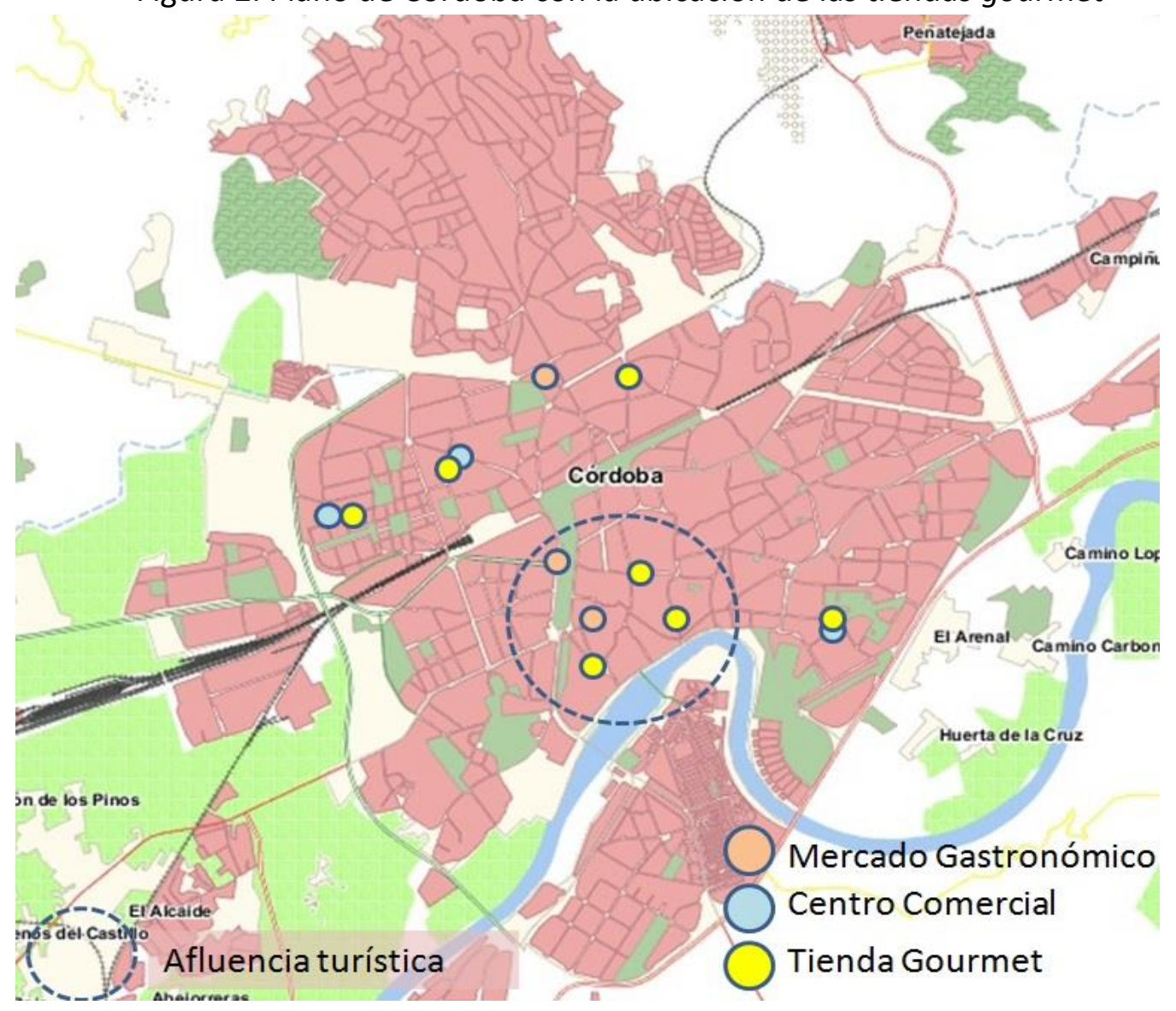

Elaboración propia

Lo cierto es que tanto la administración local y regional como los comerciantes y consumidores han acabado por darse cuenta de la importancia de contar con el comercio 
especializado de cara a la dinamización y valorización de una determinada área urbana, como ha ocurrido en otras muchas ciudades (Espinosa, 2009). No obstante, esto no implica, como veremos luego, que exista realmente una interacción real y sustantiva entre el comercio minorista, la ciudad y el turismo o al menos con capacidad suficiente de generar una sinergia comercial importante en la que se implique directamente al territorio urbano en el que se localizan los establecimientos.

Con respecto a la forma de promocionar y publicitar las tiendas, el $100 \%$ de las respuestas indica que se opta por utilizar los diversos medios publicitarios conocidos que no supongan coste significativo y que incidan sobre todo en dar a conocer la ubicación de la tienda gourmet (Tabla 2).La organización de catas, muestras, degustaciones o promociones específicas directas no suele estar entre las prioridades de estas tiendas, lo que debería ser objeto de otra investigación sobre este subsector comercial con el objeto de determinar si la causa radica en la no confianza de beneficio de retorno por parte de los comerciantes o en la dificultad de atracción de la demanda turística en una ciudad como Córdoba con una estancia media muy corta y flujos turísticos de paso o de carácter excursionista con poco tiempo de participar en eventos gastronómicos. 
Tabla 2. Aspectos de comercialización de los productos y su vinculación con rutas gastronómicas

\begin{tabular}{|c|c|c|}
\hline Pregunta & & Porcentaje \\
\hline Medio utiliza para publicitarse & $\begin{array}{l}\text { Página web propia. } \\
\text { Folletos Comerciales } \\
\text { Agencias de Viajes } \\
\text { Ferias, exposiciones... } \\
\text { Notas de prensa, relaciones con los medios... } \\
\text { Otros (indicar)../ Revistas especializadas/ } \\
\text { Denominaciones de Orígenes/ Cámara de } \\
\text { Comercio/ Redes Sociales/... } \\
\text { Dos o más formas de promocionarse }\end{array}$ & $\begin{array}{l}0 \% \\
0 \% \\
0 \% \\
0 \% \\
0 \% \\
0 \% \\
0 \% \\
\end{array}$ \\
\hline $\begin{array}{l}\text { En el escaparate de su } \\
\text { establecimiento: ¿tiene visibles } \\
\text { productos de las Denominaciones de } \\
\text { Origen de la provincia? }\end{array}$ & $\begin{array}{l}\text { Sí en todas las épocas del año } \\
\text { Sí, pero solo en algunas épocas del año } \\
\text { No }\end{array}$ & $\begin{array}{c}90 \% \\
10 \% \\
0 \%\end{array}$ \\
\hline $\begin{array}{c}\text { ¿Dentro de los productos expuestos en } \\
\text { su tienda, existe algún apartado o } \\
\text { rincón dedicado a Córdoba? }\end{array}$ & $\begin{array}{l}\text { Sí } \\
\text { No }\end{array}$ & $\begin{array}{l}100 \% \\
0 \% \\
\end{array}$ \\
\hline $\begin{array}{c}\text { ¿Vienen comerciales o representantes } \\
\text { de Rutas gastronómicas de la provincia } \\
\text { de Córdoba a mostrar y enseñar las } \\
\text { rutas existentes? }\end{array}$ & $\begin{array}{l}\text { Sí } \\
\text { No }\end{array}$ & $\begin{array}{l}30 \% \\
70 \%\end{array}$ \\
\hline $\begin{array}{c}\text { ¿Cree que es un buen argumento de } \\
\text { venta el utilizar productos bajo la } \\
\text { D.O.P o I.G.P de Córdoba? }\end{array}$ & $\begin{array}{l}\text { Sí } \\
\text { No }\end{array}$ & $\begin{array}{l}90 \% \\
10 \%\end{array}$ \\
\hline $\begin{array}{c}\text { Si un Turista le pregunta lugares para } \\
\text { visitar: ¿'Recomienda realizar rutas } \\
\text { gastronómicas en la provincia de } \\
\text { Córdoba? }\end{array}$ & $\begin{array}{l}\text { Sí } \\
\text { A veces } \\
\text { No }\end{array}$ & $\begin{array}{l}50 \% \\
35 \% \\
15 \%\end{array}$ \\
\hline $\begin{array}{l}\text { ¿Cómo valoraría la inclusión de la } \\
\text { tienda gourmet restaurante en una } \\
\text { ruta gastronómica de la provincia para } \\
\text { atraer el turismo a su establecimiento? }\end{array}$ & $\begin{array}{l}\text { Muy positiva } \\
\text { Positiva } \\
\text { Indiferente }\end{array}$ & $\begin{array}{c}70,00 \% \\
30,00 \% \\
0,00 \%\end{array}$ \\
\hline
\end{tabular}

Elaboración propia

Habría que destacar en este punto la poca participación de las tiendas gourmet en los medios de difusión y promoción turística de la ciudad y de las rutas gastronómicas existentes. De hecho, se percibe una manifiesta ausencia de información en las OITs, los guías turísticos de Córdoba y las rutas, webs y portales turísticos oficiales; aspecto éste que habría que corregir. 
Con respecto a la percepción del propietario o gestor del establecimiento sobre el turismo en Córdoba y las oportunidades que este sector representa para sus negocios, más del $50 \%$ de los encuestados lo consideran buena, pero es significativo que un $40 \%$ de los mismos no perciba el turismo como suficientemente consolidado para actuar como "nicho de mercado" importante. Los resultados prácticamente se repiten si analizamos el conocimiento que creen que tienen los turistas sobre este tipo de establecimientos y los productos que ofertan: más del $50 \%$ de los mismos sí tendrían conocimiento previo sobre establecimientos y productos que compran y en torno a un $40 \%$, no (Gráfico 2 ).

Gráfico 2. Valoración de la situación actual del turismo y el conocimiento que tienen los turistas de productos y rutas gastronómicas

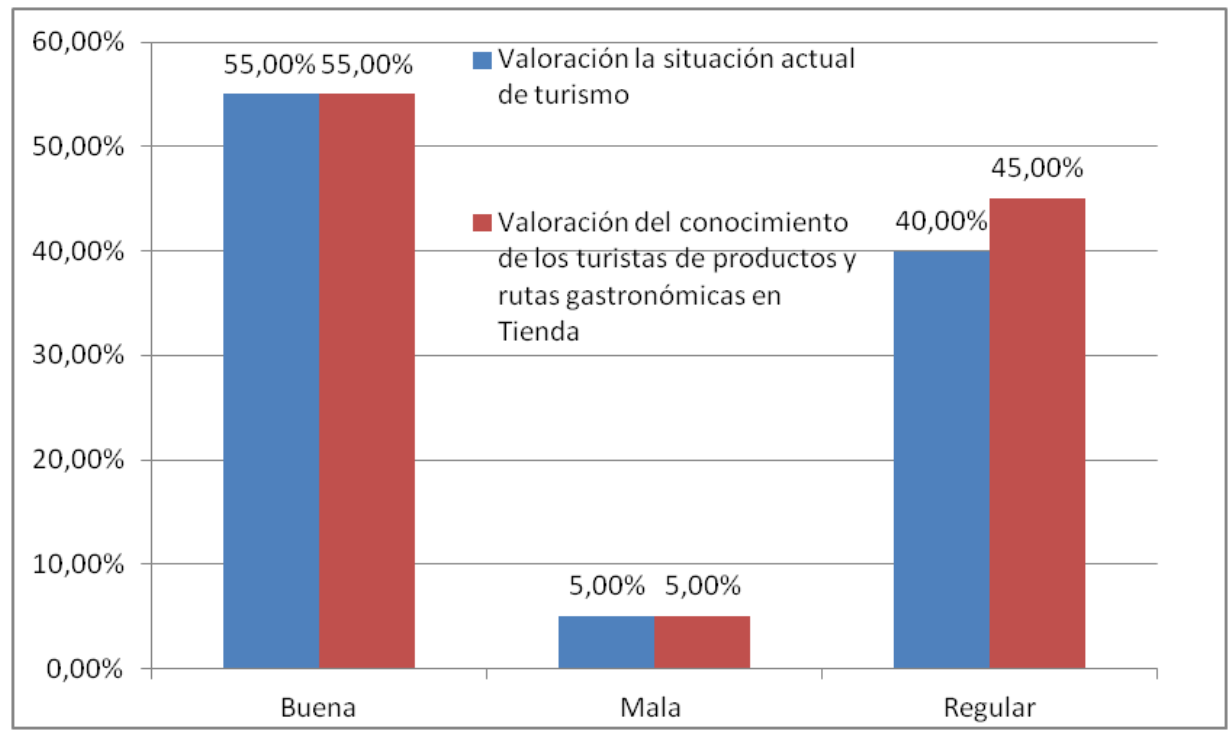

Elaboración propia

Con respecto a la comercialización de productos de la provincia y de las rutas gastronómicas, el $90 \%$ de las tiendas gourmet en Córdoba ofertan estos productos, que constituyen, además, la oferta más promocionada por estos establecimientos, intentándolos vincular siempre con las D.O.P o I.G.P. existentes y dedicando una sección privilegiada de la tienda a los productos de Córdoba capital con su respectivo merchandaising. Como contrapunto, no suelen informar ni tan siquiera dar referencias sobre las rutas gastronómicas de Córdoba y provincia relacionadas con dichos productos agroalimentarios. Es sintomático, por tanto, que mientras los comerciantes encuentran como una buena oportunidad y argumento de venta la referenciación geográfica de calidad al cliente de sus productos agroalimentarios, en cambio no se perciba como un valor añadido significativo la vinculación de los mismos con rutas turísticas gastronómicas y la imagen de marca que éstas puedan ofrecer como paraguas promocional de dichos productos.

Pese a estos últimos resultados, sin embargo, los comerciantes manifiestan que suelen recomendar a sus clientes la visita a entornos de municipios y localidades de la provincia y a la propia ciudad de Córdoba vinculados con los productos gastronómicos, aunque sin apenas saber identificar las rutas gastronómicas existentes y sin tener información importante de las 
mismas. Por su parte, un 35\% de las tiendas sólo recomiendan visitas muy puntualmente y un $15 \%$ ni tan siquiera en alguna ocasión (Gráfico 3).

Gráfico 3. Recomendaciones para visitar entornos, localidades o rutas gastronómicas en la provincia de Córdoba

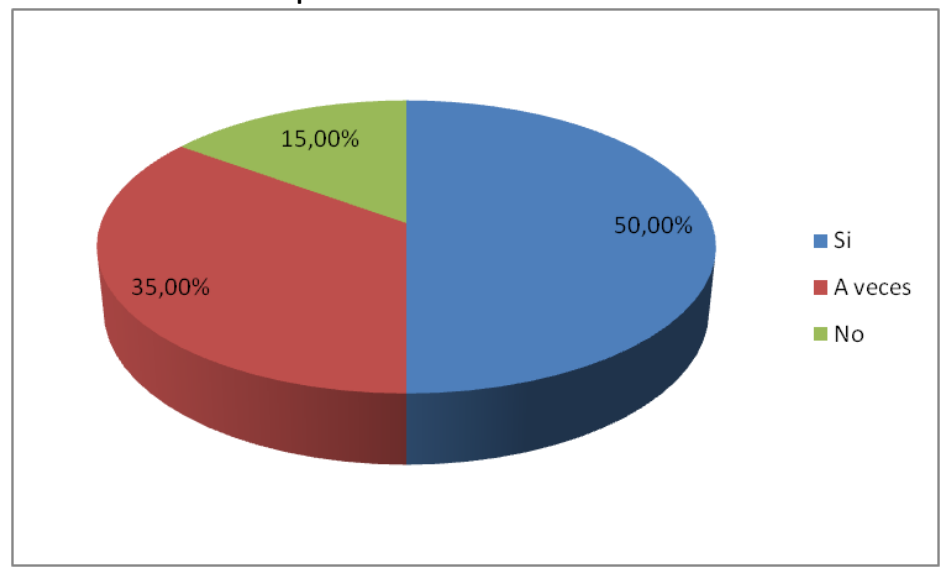

Elaboración propia

Sobre la cuestión planteada en torno a las barreras o debilidades existentes en Córdoba para el desarrollo y consolidación del turismo gastronómico y su mayor vinculación y sinergias con el comercio, el 45,00 \% de los comerciantes de tiendas gourmet indican que existe descoordinación de acciones entre las distintas administraciones públicas, como es el caso de la comercialización solapada y poco conjunta que realizan entidades como el Patronato Provincial de Turismo (Diputación de Córdoba), el Consorcio Municipal de Turismo de Córdoba y la propia Administración Turística Regional de Andalucía (Tabla 3). Por añadidura, son escasas también las sinergias interempresariales entre las tiendas gourmet, los establecimientos hoteleros y los restaurantes, manifestándose un fuerte aislamiento funcional y un comportamiento estanco que refleja la escasa integración del sector agroalimentario, el sector HORECA y el turístico en la cadena de valor de la gastronomía cordobesa. 
Tabla 3. Aspectos cualitativos sobre el turismo urbano en los clientes

\begin{tabular}{|c|c|c|}
\hline $\begin{array}{l}\text { ¿Cómo valora usted la situación actual } \\
\text { en número de turistas gastronómicos } \\
\text { que visitan tiendas gourmets en la } \\
\text { zona? }\end{array}$ & $\begin{array}{l}\text { Buena } \\
\text { Mala } \\
\text { Regular }\end{array}$ & $\begin{array}{c}55,00 \% \\
5,00 \% \\
40,00 \%\end{array}$ \\
\hline $\begin{array}{l}\text { ¿Cómo valora usted los conocimientos } \\
\text { sobre productos o materia prima de la } \\
\text { provincia de Córdoba que tiene el } \\
\text { turismo gastronómico que visita el } \\
\text { establecimiento? }\end{array}$ & $\begin{array}{l}\text { Buena } \\
\text { Mala } \\
\text { Regular }\end{array}$ & $\begin{array}{c}50,00 \% \\
5,00 \% \\
45,00 \%\end{array}$ \\
\hline $\begin{array}{l}\text { Realiza cursos o formación de cara a } \\
\text { clientes en cuanto al concepto de } \\
\text { Denominación de Origen y productos } \\
\text { autóctonos de la provincia (catas de } \\
\text { vino, catas de aceite, catas de } \\
\text { queso...etc.). }\end{array}$ & $\begin{array}{l}\text { Continuamente } \\
\text { Ocasionalmente } \\
\text { Nunca }\end{array}$ & $\begin{array}{l}20 \% \\
50 \% \\
30 \%\end{array}$ \\
\hline $\begin{array}{l}\text { El personal que atiende al Turista: } \\
\text { ¿tiene conocimiento de las rutas } \\
\text { gastronómicas en Córdoba? }\end{array}$ & $\begin{array}{l}\text { Sí, todos los empleados } \\
\text { Sí, Algunos empleados } \\
\text { No }\end{array}$ & $\begin{array}{c}75 \% \\
20 \% \\
5 \%\end{array}$ \\
\hline $\begin{array}{l}\text { ¿Qué opinión tiene de los precios de } \\
\text { compra de los productos bajo D.O.P de } \\
\text { la provincia de Córdoba? }\end{array}$ & $\begin{array}{l}\text { Alto } \\
\text { Medio } \\
\text { Bajo }\end{array}$ & $\begin{array}{l}30 \% \\
50 \% \\
20 \%\end{array}$ \\
\hline $\begin{array}{l}\text { ¿Qué opina de las rutas gastronómicas } \\
\text { existentes y los productos parejos a } \\
\text { ellas? }\end{array}$ & $\begin{array}{c}\text { Las encuentro fácilmente. } \\
\text { Tengo dificultades en encontrar proveedores } \\
\text { o un buen servicio de entrega. } \\
\text { No tengo muchos conocimientos } \\
\text { actualmente. }\end{array}$ & $\begin{array}{l}60 \% \\
25 \% \\
15 \%\end{array}$ \\
\hline $\begin{array}{c}\text { ¿Cuál es la mayor barrera para el } \\
\text { desarrollo de la zona en el ámbito del } \\
\text { turismo de ruta gastronómica en la } \\
\text { provincia? }\end{array}$ & $\begin{array}{l}\text { Descoordinación de acciones entre las } \\
\text { distintas administraciones públicas. } \\
\text { Desinterés de los organismos públicos. } \\
\text { Falta de iniciativa local privada } \\
\text { Otras (Indicar) }\end{array}$ & $\begin{array}{c}45 \% \\
25 \% \\
25 \% \\
5 \%\end{array}$ \\
\hline $\begin{array}{c}\text { ¿Participa de forma activa en la toma de } \\
\text { decisiones y la planificación territorial } \\
\text { de su zona? }\end{array}$ & $\begin{array}{c}\text { Sí. ¿Cómo? } \\
\text { Asociaciones de empresarios } \\
\text { Cooperativas } \\
\text { Mancomunidad } \\
\text { CIT } \\
\text { Ayuntamiento. } \\
\text { Grupo de Desarrollo Rural } \\
\text { No }\end{array}$ & $\begin{array}{r}15,00 \% \\
\\
5,00 \% \\
0,00 \% \\
0,00 \% \\
0,00 \% \\
0,00 \% \\
0.00 \% \\
\\
85,00 \% \\
\end{array}$ \\
\hline
\end{tabular}

Elaboración propia

Preguntados, por otra parte, sobre la procedencia geográfica de los clientes de sus tiendas, se responde que en torno al $50 \%$ es visitante foráneo, bien de origen nacional o extranjero, y un $25 \%$ población local originaria de Córdoba (Gráfico 4). En cualquier caso, no suelen contar con estadísticas elaboradas de clientes y pese a la relativa importancia de la presencia de la clientela extranjera turística, es significativo que en estas tiendas no 
acostumbren a tener etiquetados informativos en inglés y no informen éstos suficientemente sobre aspectos nutricionales, de elaboración y de origen que, sin embargo, son tan apreciados por el cliente extranjero especializado.

Gráfico 4. Procedencia de los clientes que visitan las tiendas gourmets

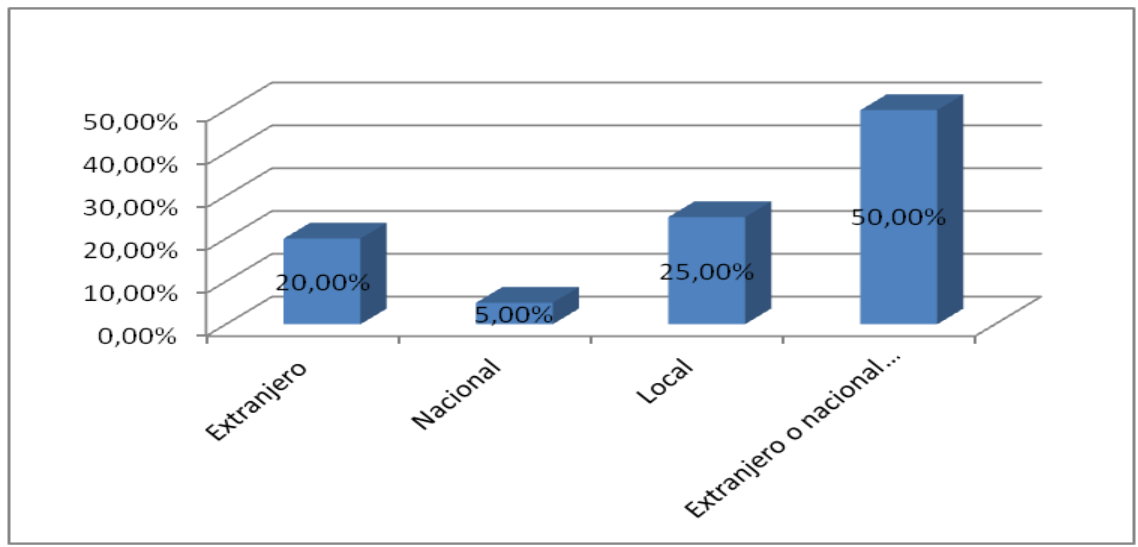

Elaboración propia

Con respecto a la integración y participación colaborativa de los comerciantes de estos establecimientos en asociaciones, redes interempresariales, Centros Comerciales Abiertos o clubes de producto, destaca el desinterés general manifestado, ya que en torno al $85 \%$ afirman que no pertenecen a ninguna entidad asociativa (Tabla 3). En las respuestas recogidas y las manifestaciones verbales recopiladas en las encuestas, se indicaron algunas razones clave, como sobre todo la falta de recursos económicos de las pequeñas pymes comerciales, el tipo de gestión familiar de los negocios que impide a los dueños poder participar en las actividades de las asociaciones e implicarse activamente en sus iniciativas.

Las dos últimas preguntas realizadas en la encuesta fueron, por su parte, relativas a la valoración del atractivo que representan los productos de la provincia para atraer el turismo (Gráfico 5) y la valoración de la inclusión de la tienda gourmet en una ruta gastronómica para atraer el turismo en el establecimiento (Gráfico 6). En el primer caso, el 85\% de los comerciantes afirmó que sí, mientras que en la segunda pregunta, un $70 \%$ dio una respuesta positiva.

Estos datos refuerzan la idea de partida con la que trabajamos en este artículo de la necesidad de que las D.O.P. y las I.G.P. de la provincia cuenten con puntos de venta de referencia en Córdoba capital, teniendo en cuenta el importante mercado de proximidad que representa la ciudad, el interés de sus comerciantes de tiendas gourmet por asumir la gestión de estos puntos y el potencial comercial que ello les representaría. 
Gráfico 5. Valoración del atractivo que representan los productos de la provincia de Córdoba para atraer el turismo

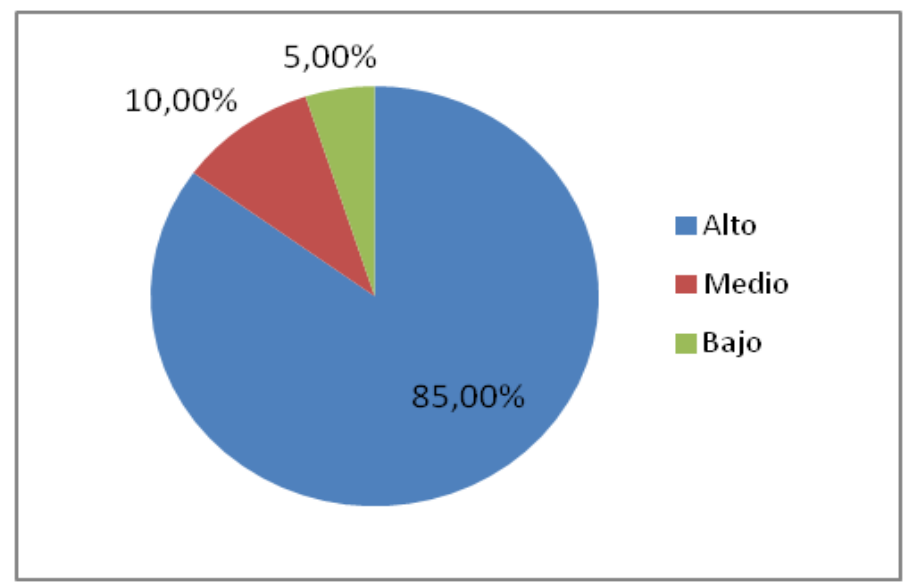

Elaboración propia

Gráfico 6. Valoración de la tienda gourmet en una ruta gastronómica de la provincia de Córdoba para atraer turismo a su establecimiento

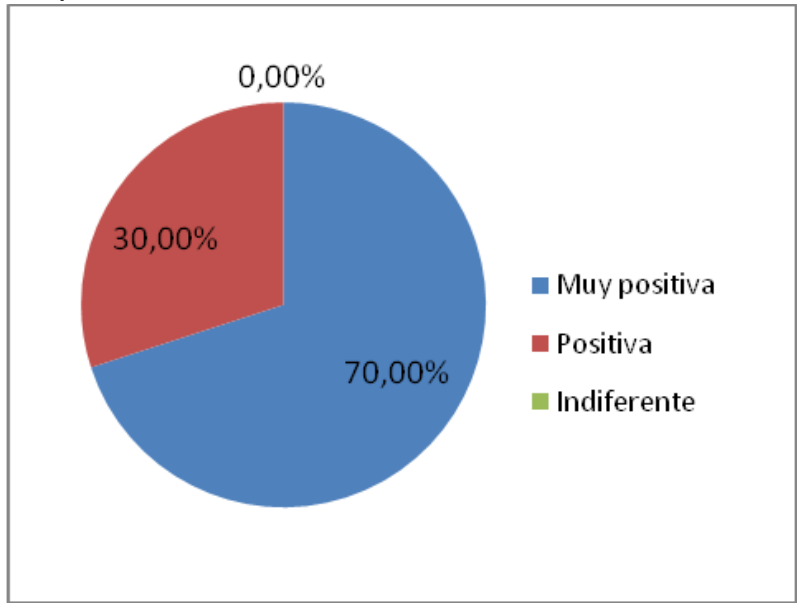

Elaboración propia

Los propietarios de tiendas gourmet compran los productos de manera separada, los exhiben de manera diferenciada y suelen tener más productos por categoría que un supermercado convencional, aunque tienen menos categorías de productos. Algunas tiendas gourmet están especializadas en un tipo o variedad de producto concreto: embutidos y jamones, quesos, mieles y mermeladas, vinos y licores, dulcería y bollería tradicional, etc. En concreto, los productos gourmet procedentes de la provincia de Córdoba con mayor presencia en el mercado nacional e internacional son los aceites de oliva de D.O.P. y los jamones y embutidos derivados del Cerdo Ibérico también con D.O.P., aunque también hay otros productos relevantes como los vinos y vinagres, la miel, los productos de caza y los dulces tradicionales.

La mayor parte de las veces estos productos, debido a su modo de elaboración o a su exclusividad, tienen un precio relativamente alto, pero lleva asociado compensatoriamente un servicio extra que ofrece el comerciante de estos establecimientos: la transferencia de este 
conocimiento al consumidor y la garantía de calidad del producto que se ofrece, intangible al mismo tiempo que de suma importancia. En ocasiones, no obstante, en estos establecimientos pueden llegar a ser más baratos que en los supermercados por su relación más directa y especial con los productores de origen. De hecho, un aspecto característico de estas tiendas es la importancia de los contactos y la confianza de los minoristas en sus clientes y sus distribuidores. Las relaciones comerciales que establecen con sus distribuidores, proveedores o marcas están muchas veces basadas en la confianza que dan los años de relación, mientras que las que tienen con los clientes son muchas veces casi personales, conocen sus gustos y preferencias y cambian la oferta de sus productos en función de la opinión de los clientes.

Por último, podemos afirmar que pese a las deficiencias de la oferta de este tipo de establecimientos que hemos analizado en Córdoba podemos afirmar que, en general, nos encontramos con una oferta de turismo gastronómico con unas expectativas positivas pero aún poco desarrolladas y optimizadas por la existencia de algunos problemas y debilidades que constriñen su consolidación.

\section{CONCLUSIONES}

En primer lugar, la práctica totalidad de las tiendas gourmet de Córdoba tienen una estructura propia de micropymes con un solo establecimiento y, por tanto, cuentan con escasos recursos y medios propios, económicos, materiales y de recursos humanos, para afrontar su desarrollo. Este problema se agudiza en la medida en que existe un importante aislamiento funcional con respecto a otros agentes locales que participan en inciden en la cadena turísticoagroalimentaria de la ciudad, pese a que la mayoría de estos establecimientos se localizan en la zona de mayor afluencia turística y comercial de la misma.

Por otro lado, es de destacar que estas tiendas comercializan prioritariamente y de manera abrumadora productos locales o provinciales cordobeses de origen y que los mismos se exponen de manera preferente en sus expositores y escaparates (un $90 \%$ de los establecimientos). No obstante, resulta sintomático que ningún establecimiento tenga acuerdo o convenio de colaboración con alguna D.O.P. o I.G.P., ruta gastronómica local o provincial, club de producto o movimientos innovadores tipo SlowFood, Cocina Kilómetro 0, Local Food o Food Miles, por lo que es necesario generar espacios de diálogo y encuentro colaborativo entre las tiendas gourmet y los diferentes agentes implicados en la actividad turística gastronómica del destino. Incentivar la generación de sinergias entre estos actores se revela, en fin, como fundamental para asegurar la viabilidad de muchos productos turísticos gastronómicos como los propios establecimientos gourmet y poner en valor turístico los recursos existentes, todo ello para evitar el aislamiento funcional y productivo de las ofertas individuales y configurar una amplia variedad de "experiencias gastronómicas" bien estructuradas y exitosas.

Pese al importante papel que podrían representar las tiendas gourmet para la reestructuración y renovación de la actividad comercial en el Conjunto Histórico de la ciudad de Córdoba, e igualmente para la oferta gastronómica local como factor y valor añadido de atracción de la demanda turística, lo cierto es que se advierten pérdidas de oportunidades al no

Investigaciones Turísticas

$N^{\circ} 13$, enero-junio 2017, pp. 178-203 
estar debidamente integradas y ensambladas con la ciudad, la oferta turística gastronómica en particular y la oferta turística urbana en general (rutas y excursiones, D.O.P. e I.G.P., agenda de eventos gastronómicos, recursos patrimoniales y paisajísticos, equipamientos e infraestructuras turísticas, agentes locales turísticos, promoción institucional, etc.).En consecuencia, se hace necesaria la redefinición de la estrategia comercial y de sostenibilidad de las tiendas gourmet, para lo cual ha de partirse en primer término de una mejora importante de la interacción entre los comercios, máxime cuando se han especializado en determinados tipos de productos y atraen a un mismo perfil de consumidor, como hemos advertido en los establecimientos de la zona turística Judería-La Ribera-Centro Histórico. Y es que en este último caso sus comerciantes han confiado más en este entorno urbano como factor de localización que en el resto de la oferta turística y comercial preexistente, surgiendo de manera espontánea, con un cierto grado de concentración de forma orgánica pero sin planificación posterior y sin apenas sinergias entre ellos.

Esta redefinición ha de basarse en un conjunto de acciones que les permita diferenciarse de sus competidores, atraer nuevos clientes provenientes sobre todo de la propia demanda turística creciente y aumentar, en definitiva, sus ventas. En este sentido, podemos señalar las siguientes medidas:

1.) Una mayor profesionalización de los comerciantes y un mejor conocimiento del sector turístico local que afiance su interacción y sinergias con éste.

2.) La mejora y personalización en la atención al cliente y su mayor orientación funcional hacia los perfiles de la demanda turística, lo que permitiría diversificar y desestacionalizar la clientela, además de favorecer la fidelización del cliente y la individualización del acto de venta.

3.) Mejorar la capacidad de innovación comercial y la introducción de nuevos productos, incluidos los de la cocina étnica y certificada (cocina Halal y Kosher, por ejemplo), demandada por determinados turistas foráneos y población inmigrante.

4.) Mayor vinculación de las tiendas gourmet con las D.O.P. e I.G. mediante convenios de colaboración, promociones conjuntas, establecimientos prescriptores o asociados como puntos de venta, etc.

5.) Una integración funcional con el sector de la hostelería y el turismo de la ciudad, tanto a nivel interempresarial como a nivel de colaboración mutua con las Administraciones con competencias en fomento y promoción del turismo, dadas las potencialidades advertidas en el segmento del turismo gastronómico en Córdoba.

6.) La promoción de los establecimientos y productos culinarios especializados bajo el paraguas de las marcas geoturísticas de Córdoba y provincia y una planificación turísticocomercial conjunta de aquellas acciones de interés mutuo para ambos subsectores de actividad económica.

Por tanto, para que las tiendas gourmet formen parte del producto turístico gastronómico de Córdoba y provincia, y siguiendo el ejemplo de otros productos gastronómicos (Prat y Canóves, 2014), es necesario poner en marcha unas estrategias que ayuden, en primer lugar, a crear unas redes sociales entre los agentes involucrados con este turismo. $Y$ 
posteriormente habría que aumentar la dinámica relacional de dichas redes, con la participación activa y comprometida de todos los agentes involucrados en el proceso, sean públicos o privados, creando unas relaciones densas, permanentes y eficaces que se identifiquen en todo momento con el territorio y pongan en valor la zona geográfica, partiendo de un producto de calidad comercializado en ese tipo de tiendas y dentro de una ruta turística que forme parte del atlas geográfico gastronómico de la zona.

\section{REFERENCIAS BIBLIOGRÁFICAS}

Alvares, I. y Alvares de Luis, A. (2012). Estilos de vida y alimentación. Gazeta de Antropología, 25(1), 1-13.

Armesto, X. A. y Gómez, B. (2004). Productos agroalimentarios de calidad, turismo y desarrollo local: el caso del Priorat. Cuadernos Geográficos, 34(1), 83-94.

Boniface, P. (2003). Tasting tourism: travelling for food and drink. Burlington: Ashgate.

Clocke, P., Crang, P. y Goodwin, M. (2011). Introducing Human Geographies. London: Arnold.

Consorcio de Turismo de Córdoba (2016). Informe Anual del Observatorio de Turismo de Córdoba, 2015. Córdoba: Ayuntamiento.

Escuela de Organización Industrial (2014). Plan estratégico de Turismo de Córdoba 2015-2019. Córdoba: Ayuntamiento de Córdoba.

Eseca (2010). Informe Anual del Observatorio Turístico de Córdoba. Córdoba: Ayuntamiento.

Espinosa, A. (2009). El comercio como herramienta estructuradora del territorio. El caso de las ciudades alicantinas. Alicante: Universidad de Alicante.

Espinosa, A. (2011). La especialización del sector minorista de alimentación en Dortmund (Alemania). Investigaciones Geográficas, 56, 97-112.

Fandos, C., Blanco, H.J. y Puyuelo, A. J. (2012). Gastronomy's importance in the development of tourism destinations in the world. En P. Jordan (Ed.), Global Report on Food Tourism (pp. 69). Madrid, OMT.

Hall, C. M. y Page, S. J. (1999). The Geography of Tourism and Recreation: environment, place and space. London: Routledge.

Hall, M., Sharples, I., Mitchell, R., Maciony, N. y Cambourne, B. (Eds.). (2003). Food tourism around the world: development, management and market. Oxford: ButterwotHeinemann/Elsevier.

Hernández, R., Millán, M. G, y Dancausa, G. (2016). Tourism Observatory: a need for management and gastronomy of Cordoba province. International Journal of Scientific Management and Tourism, 2(4), 69-80.

Indap. Gobierno de Chile (2010). Informe Final: análisis de la industria delicatessen nacional. Chile, Universidad Central de Chile.

Leal, M. P. (2013). Turismo gastronómico y desarrollo local en Cataluña: el abastecimiento y comercialización de los productos alimenticios (Tesis doctoral). Universidad de Barcelona.

López, T. y Sánchez, S. M. (2012). La gastronomía como motivación para viajar. Un estudio sobre el turismo culinario en Córdoba. Pasos. Revista de Turismo y Patrimonio Cultural, 10(5), 575-584. 
Márquez, A. M. y Hernández, M. J. (2001). Cooperación y sociedades cooperativas: el caso de la Denominación de Origen Sierra Mágica. Revista de Estudios Cooperativos, Revesco, 74, 123149.

Merinero, R. y Zamora, E. (2009). La colaboración entre los actores turísticos en ciudades patrimoniales. Reflexiones para el análisis del desarrollo turístico. Pasos. Revista de Turismo y Patrimonio Cultural, 7(2), 219-238.

Millán, M. G. (2011). Las empresas alimentarias como nuevo motor del turismo industrial en la provincia de Córdoba. Análisis del perfil del turista. Rotur. Revista de Ocio y Turismo, 4, 89116.

Millán, G. y Hernández, R. (2015). Análisis de la oferta en restauración de la ciudad de Córdoba y su implicación con las rutas gastronómicas de la provincia. TURYDES. Revista de investigación en turismo y desarrollo Local, 8(18), 1-13.

Millán, G. y Morales, E. (2012). Denominaciones de Origen Protegidas (D.O.P.) y turismo gastronómico: una relación simbiótica en Andalucía. Gran Tour: Revista de Investigaciones Turísticas, 6, 101-121.

Muñoz, L. (2010). La distribución de productos gourmet en Estados Unidos. Madrid: Instituto Español de Comercio Exterior (ICEX).

Oliveira, S. (2011). La gastronomía como atractivo turístico primario de un destino. Estudios y Perspectivasen Turismo, 20(3), 738-752.

Olvera, M. (2006). Lanouvellecuisine: evolución y situación actual de la cocina contemporánea. Puebla: Universidad de las Américas.

Petrini, C. (2007). Bueno, limpio y justo: principios de una nueva gastronomía. Madrid: Polifemo.

Prat, J. M. y Cànoves, G. (2014). Las rutas del vino del Empordà y del Priorat y su dinámica relacional. Dos destinos con diferente grado de desarrollo del turismo enológico y una dinámica relacional similar. Estudios Geográficos, 75(277), 683-705.

Regina G. S. y Daniela T. (2008). Gastronomía y turismo en Argentina. Polo gastronómico Tomás Jofré», Pasos. Revista de Turismo y Patrimonio Cultural, 6(2), 249-268.

Richards, G. (2002). Gastronomy: An essential ingredient in tourism production and consumption. Tourism and gastronomy (pp. 3-20). London: Routledge.

Scarpato, R. (2002).Gastronomy as a Tourist Product: The Perspective of Gastronomy Studies. En A. M. Hjalager, y G. Richards (Eds.), Tourism and Gastronomy (pp. 51-70). New York: Routledge.

Torres, C. A. (2012). La participación de las grandes cadenas de supermercados en las redes de comercialización de los pequeños productores. Nueva antropología, 25(77), 109-132.

Treserras, J., Medina, X. y Matamala, J. C. (2007). El patrimonio gastronómico como recurso en las políticas culturales y turísticas en España: el caso de Cataluña. En J. Tresserras, y X. Medina (Eds.), Patrimonio gastronómico y turismo cultural en el Mediterráneo (pp. 217242). Barcelona: Ibertur.

Villegas, A. (2012). Córdoba Gastronómica. Córdoba: Almuzara.

Vizcaíno, M. L. (2015). Evolución del turismo en España: el turismo cultural. International Journal of Scientific Management and Tourism, 1(4), 75-95.

Watts, D. Ilbery, B. y Maye, D. (2005). Making re-connections in agro-food geography: alternative systems of food provision. Progress in Human Geography, 29, 22-40. 
Weatherell, C., Tregear, A. y Allinson, J. (2003). In research of the concerned consumer: UK public perception of food, farning and buying local.Journal of Rural Studies, 19(2), 233-244.

Whelan, A., Wrigley, N., Warm, D. y Cannings, E. (2002). Life in a'food desert'. Urban Studies, 39(11), 2083-2100.

Para citar este artículo: Hernández Rojas, R.D.; Rivera Mateos, M.; Millán Vázquez de la Torre, G. (2017). La integración de los productos agroalimentarios de las tiendas "gourmet" en la oferta turística gastronómica de la ciudad de Córdoba. Investigaciones Turísticas, (13), 178-203. http://dx.doi.org/10.461/INTURI2017.13.09 